\title{
"Los castigos del rey de Mentón". Un ejemplo de fusión de tradiciones en el Zifar
}

\author{
Ana María Morales*
}

\section{Resumen:}

El libro del Caballero Zifar podría ser visto como la reconciliación de las distintas tradiciones que en su momento convivían en la Península Ibérica: en él conviven lo mismo un relato de corte bretón y cortés que otros de azarosas aventuras de estilo helenístico con colecciones de sentencias -occidentales o no- y cuentos orientales. En ocasiones este carácter múltiple ha provocado que la crítica prefiera marcar lo heterogéneo de los materiales que conforman el Zifar y considerarlo una colección de textos más que una obra narrativa mientras intenta inclinar hacia una u otra tradición (oriental u occidental) las fuentes o influencias de su génesis y la especificidad de su forma. Este trabajo trata de encontrar las relaciones que tienen "Los castigos del rey de Mentón", una de las partes que con más facilidad se asumen como independientes, con el resto de la obra.

Palabras clave:

Caballero Zifar, preceptivas morales, libros de caballerías, espejos de príncipes, colecciones de sentencias.

Tal vez es un lugar común apuntar que una obra como El libro del Caballero de Dios o El libro del Caballero Zifar, donde se reúnen y complementan tantas diferentes tradiciones y tendencias, sólo pudo

\footnotetext{
* Universidad Nacional Autónoma de México-FFyL.
} 
ser producto de la España del siglo XIV; pero, no por tópico, deja de ser cierto. España, durante este periodo, es un espacio privilegiado para la confluencia de distintas tradiciones literarias; su situación geográfica y política la convirtió en un foro aglutinador en el que podían encontrarse lo mismo cultivadores de la más moderna poesía romance que escritores de las más cultas formas poéticas árabes, por no mencionar la enorme actividad popular que forjaba y reforjaba formas mixtas o más apegadas a una u otra tradición. ${ }^{1}$ Sin embargo, en pocas obras españolas pueden dejarse sentir tan evidentemente estas tradiciones tan diversas como en el Zifar: a la fama y fortuna de las obras caballerescas y de aventura que, iniciadas en Francia siglos atrás, habían conquistado Europa entera, debería sumarse el éxito -constatado por las numerosas traducciones y copias que se conservan o de las que se tiene noticia- de un gran número de escritos árabes que estaban en uso y se intercalaban con liberalidad en trabajos hispanos, ${ }^{2}$ el Zifar se origina en ese momento en que el intercambio de fuentes y préstamos de materias aún no se podía suponer lesivo para el valor de las obras.

Siendo así, siendo el Zifar producto de este tiempo, de este espacio, ¿cómo sentir extrañeza ante su característica fusión de elementos provenientes de orígenes diversos y con objetivos narrativos dispares? ¿Cómo intentar orientar sus fuentes e inspiración en una sola dirección? Ya Marcelino Menéndez y Pelayo había notado la heterogeneidad del texto al referirse al libro de caballerías como "un specimen de todos los géneros de ficción y aun de literatura doctrinal que hasta entonces se habían ensayado en Europa" (295). El

${ }^{1}$ Habría que recordar también que el mismo siglo XIV presenta en la Península una gran expansión en lo que a maneras de narrar se refiere; es el momento en el que la mayor parte de las lenguas romances ya se consideran aptas para la experimentación narrativa y se permiten abandonar su carácter genético de traducción para incorporar elementos dispares y preferir la fusión de tradiciones.

${ }^{2}$ Véase, por ejemplo, el estudio de John K. Walsh, "Versiones peninsulares del «Kitāb Àdāb Al-Falāsifa» de Hunayn Ibn Ishāq", donde el autor hace una excelente revisión de cómo se puede reconstruir un texto árabe (el Libro de los buenos proverbios) usando las traducciones al castellano y al latín que tan frecuentes eran en la España de los siglos XII, XIII y XIV. 
Libro del caballero Zifar, texto variopinto donde conviven lo mismo un relato de corte bretón y cortés que otro de azarosas aventuras de estilo helenístico con colecciones de sentencias y cuentos orientales, es un ejemplo estupendo en el cual se puede estudiar la impresionante multiplicidad de formas discursivas que se origina por la intersección de culturas diferentes y la eclosión de las narraciones en lengua romance. Sin embargo, una buena parte de la crítica que se ha ocupado del Zifar ha descuidado este carácter heterogéneo y pretendido cargar hacia una u otra tradición (oriental u occidental) las fuentes o influencias de su génesis y la especificidad de su forma. ${ }^{3}$ Por este camino, los partidarios de la corriente orientalista han pretendido ver en la intención didáctica de la novela uno de los más sólidos argumentos para emparentarla con las literaturas árabes - pues también es lugar común mencionar el acentuado carácter didáctico que suele encontrarse en las literaturas orientales-, ${ }^{4}$ soslayando una de las actitudes predominantes en la Edad Media

${ }^{3}$ Hay, sin embargo, una importante excepción en este terreno: Roger M. Walker, a propósito del tono moral del libro -y contestando a algunas afirmaciones que María Rosa Lida de Malkiel hace sobre el carácter anómalo del Zifar en "Arthurian Literature in Spain and Portugal" (414) - se pregunta si "Is not possible that at least some of the puzzling points about the work's moral tone may, in fact, be reflections of Islamic and Arabic rather than Christian and European ideals?" (50). En su libro, Walker intenta ver todas estas tradiciones dispersas en la península Ibérica y encontrarlas reconciliadas y juntas en el Zifar.

${ }^{4}$ Debido a que en España la dominación árabe se hizo casi sinónimo de dominación islámica, nos hemos acostumbrado a hablar de literatura árabe como de un conjunto de literaturas de diversas lenguas y tradiciones cuyo único denominador común era el haberse desarrollado o cultivarse en territorios bajo la supremacía del Islam, y es así como empleo el adjetivo. Ahora bien, si resulta cierto que a la España no árabe la parte que más le interesó de las expresiones de estas literaturas fue la que estaba teñida por la intención didáctica (existe un gran bagaje de exempla y refranes traducido e incorporado en diversos escritos de los reinos cristianos), sería harto arriesgado dejar descansar sólo sobre la intención didáctica la pertenencia a una u otra tradición cuando sabemos que la literatura medieval en su conjunto sintió una gran afición por los mensajes morales y los contenidos didácticos de las obras literarias, mismos que pueden rastrearse en textos de cualquier tradición y casi de cualquier género. Es cierto que si bien la primera prosa en árabe estaba profundamente influida 
cristiana, que también intentó encontrar en las obras de sus distintas literaturas romances lecciones de moral, religión o política, ya invocando a Horacio ya la edificación cristiana.

Entre estas obras se encuentran los espejos de príncipes, la preceptiva moral, social y política que en un primer momento se empleó para ilustrar a futuros monarcas, señores feudales, consejeros y nobles sobre las reglas del bien obrar. ${ }^{5} \mathrm{Y}$, efectivamente, la cultura musulmana produjo obras de propósitos educativos, y para príncipes y nobles, durante varios siglos, en la propia península Ibérica. Sólo del reino de Granada pueden mencionarse el Concierto para exhaustivamente tratar lo que con los caballos se puede relacionar, de Muhammad ibn Ridwan ibn Arqam, autor del siglo XIII; el Cúlmen beneficioso y provisor de lo que no contiene el "Concierto...", de ibn Arqam y Reparación de los temas que no trae a colación, de Abd Allah ibn Muhammad ibn Yuzayy, autor del siglo XIV; y tres de ibn Hudayl: el Regalo de los espiritus y blasón de los andaluces, la Gala de caballeros, blasón de paladines-versión modificada de la precedente y que, como aquélla, está dedicada a la hipología- y los Provechos trazados de la albeitería, sobre hipiatría; las tres del siglo XIV (Viguera 16-24). También de la literatura musulmana proceden obras como la Lámpara de los reyes, de Aben-Abi-Bandaka; El huerto de los reyes, de Aben el

por los habits (relatos o parábolas de una acción que se remonta a tiempos del profeta) y por las enseñanzas de los qussas (predicadores populares) pronto la prosa literaria se apartó de estos modelos y no tardaron en fijarse géneros híbridos en los cuales 'La prose devient un véhicule 'ad omnia'. Les écrivains ont le goût ou la démangeasion d'écrire et ils disposent d'un outil plus docile. Nous avons des ouvrages de toutes sortes: théologie, droit, moral, exégèse coranique, traditions, linguistique (grammaire, lexicographie, prosodie), philosophie, histoire, géographie, sciences exactes, mystique" (Abd-El-Jalil 104). El carácter mixto y pocas veces únicamente literario de estas primeras obras predispuso la recepción que la prosa árabe tuvo en los círculos cristianos donde se le identificó con mayor facilidad por su contenido que por su intención artística.

${ }^{5}$ Posteriormente, esta literatura didáctica cambió de función dirigiéndose hacia consejeros y después a filósofos, con lo cual se convirtió en literatura meditativa y de reflexión más que de formación de futuros gobernantes. 
Jabit, y El collar de perlas, de Muza II de Tremesen, que influyeron con fuerza en los primeros libros de preceptiva política escritos en España para educar reyes.

Sin embargo, sin menospreciar la eminente influencia de las galas de príncipes, no es posible descuidar la cultura occidental, particularmente la tradición cristiana, que también podía proporcionar pautas de índole genérica bastante precisa por lo menos desde el siglo XIII, cuando Egidio de Colonna inaugura una serie de tratados doctrinales de gobierno que expande su onda hasta el siglo XVII, con el libro De regimine principum, glosado y traducido por fray Juan García de Castrogeriz. ${ }^{6}$ A esto puede sumarse la práctica común en la Edad Media de hacer resúmenes didácticos de obras de autores antiguos, de los cuales uno de los favoritos fue Séneca. Estas versiones fueron fuente de la mayor parte de la preceptivas morales tardomedievales y renacentistas. Por lo que atañe directamente a las preceptivas regias, la Edad Media recoge desde Isócrates y san Agustín "un fondo parenético que va construyendo la literatura consiliarista" (Pérez 347). Tampoco puede desestimarse la predicación cristiana, en la que María Rosa Lida sitúa sin hesitación el origen de todo influjo del hábito de usar ejemplos en la literatura medieval: "la abundancia de exempla en las obras medievales no se

${ }^{6}$ Donde se cita a Zifar al lado de Tristán y Amadís. Por otra parte, anteriores, y presumiblemente separados de la influencia oriental, existen numerosos tratados políticos y morales, como podría ser el Policratus de John de Salisbury -producto de la corte normanda de Inglaterra- o buena parte de la literatura caballeresca artúrica que presentó a sus personajes como espejo de caballeros y de reyes y dio origen a una auténtica reformulación en la ética y el imaginario de la elite social. Todas estas obras románicas se podrían considerar manuales de buen gobierno, aunque tal vez no espejos de príncipes. En España, ya desde el siglo XIII puede verse en el Libro de Alexandre el propósito de configurar esta imagen de buen caballero y buen príncipe en el compartimiento del monarca macedonio que se relaciona con generosidad con sus hombres, sigue los consejos de su preceptor, Aristóteles, trata con respeto a sus vencidos y es en todo momento símbolo del buen gobierno.

${ }^{7}$ Beneyto Pérez menciona, además, una larga lista de padres de la Iglesia, patriarcas, clérigos y santos que durante toda la Edad Media trabajaron en tratados de preceptiva real: Paulino de Aquileya, Jonás de Orleans, Elipando de Toledo, San Isidoro de Sevilla, San Buenaventura, Bernardo de Claraval, etc. Resultaría tediosa en 
debe al influjo clásico, sino, como es harto sabido, a la predicación cristiana que en sus ricos repertorios incluye el ejemplo grecorromano" (La tradición clásica... 352).

Ante este panorama pintado a trazos muy gruesos, realmente sorprende que el Zifar aparezca a la vista de los especialistas como una amalgama confusa de distintas tradiciones pero todas ellas orientales. Su materia compuesta y la manera expositiva que combina los relatos de caballerías con el sermo y éste con los exempla, ${ }^{8}$ pueden ser sorpresivas en un primer momento, ya que la obra se presenta como distinta de lo que acostumbramos considerar como libro de caballerías, que es el género mayor en el que lo incluimos con frecuencia, ${ }^{9}$ pero, aun viendo claramente el carácter moralizador y didáctico propio del Zifar, no por ello es posible argüir sólo esta característica para suscribirlo a una única tradición dominante.

Ahora bien, obviar el predominio del material y el propósito moralizante en el texto es imposible. De hecho, el libro puede verse en conjunto como un gran exemplum o una sola prédica; de hecho, se le ha considerado de esta manera (véase Burke); elementos suficientes hay, amén de los simbolismos y sentidos morales encubiertos

un trabajo como éste, la enumeración exhaustiva, así que prefiero remitir al capítulo XI del libro de Beneyto Pérez: "La literatura en torno al príncipe".

${ }^{8}$ Uno de los modelos genéricos o paradigmas formales adoptados desde los modelos clásicos para exponer la doctrina fue el sermo, o plática literaria, usado por Séneca el filósofo en sus tratados y cartas. El sermo filosófico-literario de Séneca fue una versión peculiar, influida por la oratoria que durante el período imperial marcó todos los géneros de la literatura romana, de la diatriba cínica. Del cinismo la adoptó el estoicismo y de éste la tomó Séneca, al incorporar las ideas del Pórtico, sólo que despojándola de rasgos que no le resultaban funcionales ni necesarios, como la agresividad y la ironía (que sí mantuvo en otra obra emparentada con la diatriba: la Apocolocyntosis del divino Claudio, sátira menipea), y aproximándola al discurso persuasivo de la oratoria, para que cumpliera con el doble objetivo de llegar a la razón y tocar los sentimientos.

${ }^{9}$ Uno de los grandes temas en la crítica del Zifar ha de ser la pertenencia al genero de los libros de caballería, pero esa cuestión central, que podría ayudar a dirimir de una vez por todas la mezcla de elementos que conforman la obra, escapa a los alcances del trabajo que aquí me he fijado. 
que pueden rastrearse desde los nombres de los personajes, y contribuyen a que incluso sea posible interpretar la obra como una gran alegoría o pueda ser leída como una vida ejemplar, más cercana a la hagiografía que a la literatura caballeresca. ${ }^{10}$ Este camino puede ser interesante y marcaría con precisión un rumbo divergente en la ruta común del libro de caballerías - entendido tantas veces como el justo contrario: obras que dilatan la moral y guían por el camino de la ligereza moral-; empero, mis propósitos son más modestos y sólo pretendo en este trabajo adscribirme a la línea que estudia una vertiente de lo educativo en el libro y examinar algunos de sus aspectos pedagógicos, esbozar un planteamiento sobre la línea de preceptiva que se sigue y demostrar cómo la tercera parte:" "Los castigos del rey de Mentón”, puede leerse como un espejo de príncipes en su más literal acepción: un tratado de la educación de futuros gobernantes. Ya que el libro tiene una sección explícitamente didáctica, la preceptiva que se enuncia en esta parte es la que será el objeto de mi análisis y no la que pudiera extraerse del libro en su conjunto.

El Zifar puede dividirse en cuatro apartados: I. El caballero de Dios, II. El rey de Mentón, III. Los castigos del rey de Mentón y IV. Los hechos de Roboam. ${ }^{12}$ Pero, en mi opinión, las dos primeras secciones tienen una unidad de contenido y discurso tal, que bien pueden considerarse como una sola y constituyen la narración de "Los hechos de Zifar"; después de ésta vienen, sin otras objeciones a la

${ }^{10}$ No debe, sin embargo, descuidarse la evidencia de que esas vidas pseudosantas que pudieran presentarse como hagiografías son en muchas ocasiones relatos muy cercanos a los de caballerías. Si es cierto que Chrétien de Troyes es el iniciador de la literatura artúrica y que sus héroes, revoltosos jóvenes que buscan amor y tierra, son el prototipo del caballero, no hay que olvidar que también escribió Guillermo de Inglaterra, leyenda hagiográfica en la que puede verse un esquema narrativo helenístico bastante similar al del Zifar.

${ }^{11}$ Esto según Wagner. Ver infra notas 12, 13 y 21.

${ }^{12}$ Philip Wagner -el primer editor moderno, si dejamos fuera la edición de Michelant de 1872 y que resulta poco fiable y muy difícil de encontrar- estableció esta división en cuatro partes, además del prólogo. 
división usual, "Los castigos del rey de Mentón” y "Los hechos de Roboam". 13

Para la crítica, uno de los más graves escollos para admitir la verdadera unidad e íntima trabazón de la novela se encuentra en la interpolación del segundo apartado del libro, "Los castigos del rey de Menton", que al parecer separa las otras partes de la novela en dicotomías y que en sí, si queremos ser puristas con el género, no tiene mayor función dentro de lo que podría considerarse el esquema tradicional de un libro de caballerías. Ahora bien, si se pretendiera seguir este camino y considerar El libro del cavallero Zifar como típico libro de caballerías, no sería la presencia de "Los castigos del rey de Menton" el único problema al que nos enfrentaríamos. ${ }^{14}$ Por otra parte, considerando la literatura de caballerías en su conjunto como un espejo y un entretenido ejemplo del bien obrar de príncipes y caballeros no es posible soslayar que toda esta "literatura de entretenimiento" podía cumplir en mayor o menor grado una

${ }^{13}$ En la edición que uso, la de Rodríguez Muela, y que está basada en el manuscrito de Madrid, no hay razones tipográficas que hagan necesaria la división en cuatro como lo señala el editor en su "Introducción crítica" (24-25).

${ }^{14}$ Dentro del roman courtois, el género caballeresco clásico, sea de materia bretona, de Francia u oriental, difícilmente sería posible concebir como protagonista adecuado a este caballero casado y con familia hábil con las armas pero cuyos mayores triunfos los logra mediante el fingimiento; un caballero errante pero no demandante, casado pero casto, con un tipo de religiosidad que raya en el misticismo y una moral que se acerca a lo que se ha considerado "de clase media" (aunque habría que recordar al menos a otro caballero casado que hace caballerías hasta que es coronado rey, Erec, de Erec y Enide, al menos a otro que no da muchas muestras de interés sexual y si de orientaciones místicas, Galahat y a otro con una moral que raya en lo clasemediero, el Tristán del Tristán en prosa). En cuanto a la estructura, tampoco estamos en el camino de héroe cuya historia inicia con sus padres y que se irá formando hasta conseguir su reino y su dama; la ordenación y episodios del Zifar responden con mayor eficiencia a la estructura de los llamados "romans de aventuras", textos de materia bizantina o miscelánea que se caracterizan por privilegiar la temática de la novela helenística -amores estorbados y aventuras azarosas o intempestivas-, aunque también dejan un espacio muy importante para la piedad, la enseñanza y la penitencia moral. Excedería con facilidad los alcances de este trabajo, entrar en la discusión sobre las objeciones que se le podrían poner al Zifar para considerarlo como libro de caballerías avant la lettre. 
función didáctica. ${ }^{15} \mathrm{Y}$ si es posible afirmar esto de novelas -más propiamente romans - al parecer ajenas por completo a una intención didáctica, como podrían ser los romans courtois de materia artúrica, no debería ser criticable en El cauallero Zifar este propósito que resulta tan evidente por las continuas orientaciones explícitas de la obra hacia esta dirección.

Y, mientras para algunos críticos "Los castigos del rey de Mentón" no pasa de ser una interpolación de diferente materia y estilo que el resto del libro y un elemento que rompe el hilo narrativo de la novela, hay quienes ven en este pasaje una pieza clave para comprender la estructura global de la obra; ${ }^{16}$ no sólo como nexo de los hechos de Zifar y las hazañas de Roboam, sino también como la explicación que las relaciona en verdad.

Como su nombre indica, "Los castigos del rey de Mentón" son diferentes consejos y amonestaciones que el caballero Zifar, ahora rey de Mentón por obra y gracia de Dios y la casualidad ex machina, da a sus hijos Garfín y Roboam. Ambos están destinados a ser reyes; Garfín, por herencia del reino de su padre, y Robam, merced su brazo y sus hazañas caballerescas. Como bien ha demostrado Wagner, tiene entre sus fuentes directas una obra oriental de carácter moral: Las flores de filosofía, y usa con soltura fragmentos de la segunda Partida de Alfonso el sabio y los Castigos y documentos del rey

${ }^{15}$ Es harto conocido el papel civilizador y moderador que cumplió la literatura caballeresca y la resonancia que tuvo en las maneras de comportarse de la sociedad altofeudal. De igual forma en que Tristán era espejo de buena crianza, Lancelot lo fue de buen amador, y si Arturo era el modelo del buen rey, Gauvain fue el parangón del perfecto caballero.

${ }^{16}$ Marta Ana Diz considera -haciéndose eco de estudiosos como Justina Ruiz de Conde, Kenneth Scholberg y James Burke- "Los castigos del rey de Mentor" como el puente necesario para la unión de la parte I y la III. Por otro lado, piensa que esta sección es la explicitación de una preceptiva que ya ha sido puesta en práctica en la primera parte de la novela y cuyos consejos serán retomados en la tercera. Dice que: "Los castigos son, pues, el eje organizador que explica la estructura de la novela. El sentido del Cifar reside precisamente en el concepto de la lección que Mentón imparte a sus hijos. La novela entera es una lección sobre el arte de la conducta [...] dirigida al lector" (113). 
don Sancho. ${ }^{17}$ De estos, hay en "Los castigos..." pasajes enteros copiados literalmente de las Flores de filosofía. ${ }^{18}$

Además de esos tres textos, sería posible seguir enumerando fuentes probables que en uno u otro momento han sido identificadas como directas o indirectas de esta sección del libro: Los Bocados de Oro, la Poridad de Poridades, la Mukhtār al-hikeam, el Kitāb adab alfalāsifa, el Sirr al-asrār, el Libro de los cien capitulos, el Moralium Dogma Philosophorum, el De regimine principum y un etcétera tan largo como puedan resistir mil quinientos años de obras de pensamiento político, moral y religioso. Esta cuestión de las fuentes es siempre espinosa, y el terreno, lejos de ser seguro, en textos como el Zifar se torna francamente aventuroso.

Así, mientras que orientalistas y medievalistas de tendencias europeizantes continúen buscando entre textos perdidos u olvidados, nada puede afirmarse, y, desde luego, en toda aclaración de esta especie debería intentarse considerar cuán problemáticas pueden ser las opciones radicales. ${ }^{19}$ En temas como estos no es seguro pronunciarse ni siquiera sobre trozos de texto que parecen trasplantados de un lugar a otro. Como bien ha notado Agapito Rey: "los frecuentes paralelismos verbales pueden obedecer a la comunidad de fuentes más que al influjo directo de un texto sobre otro" (: vii). Ahora bien, el tipo de doctrinas que se predica en "Los castigos..." también ha contribuido a propiciar este espejismo de opciones: obviamente, los consejos que Zifar ofrece a sus hijos suelen ser lo suficientemente generales para tener posibilidades de ser

${ }^{17}$ Véase principalmente el tercer apartado del artículo: "The didactic portion of the Cifar" (30-44), donde hace un excelente estudio en el que compara pasajes de estos textos con otros del Zifary muestra gráficamente los paralelismos, en especial de las Flores de Filosofía, con "Los castigos."

${ }^{18}$ Wagner da tablas de equivalencias entre los lugares en los que aparecen las leyes de las Flores... y el que ocupan en "Los castigos..." Por otra parte, la comparación que hace entre ambos textos permite constatar que efectivamente se usó el escrito árabe prácticamente verbatim.

${ }^{19}$ Roger Walker, reaccionando ante un vasto panorama de arabistas dedicados a la literatura sapiencial y que han presentado todo tipo de evidencia sobre el carácter 
reconocidos como propios por cualquiera de las culturas que convivían en la península Ibérica en el siglo XIV. La preceptiva religiosa de "Los castigos del rey de Mentón", que podría ser la que con mayor dificultad se confundiera, resulta válida y puede ser aplicada o extraída de cualquiera de las religiones que coexistían en España; ${ }^{20}$ posiblemente hay rasgos que apunten hacia alguna dirección en particular, pero esto se pierde entre el sustrato común de los sistemas religiosos cristiano y musulmán. En "Los castigos..." todas las virtudes y todos los bienes se derivan de amar, temer y servir a Dios. Esta doctrina, así como los consejos sobre la conveniencia práctica de guardar sus mandamientos y la de honrar a los padres y sacerdotes, sin duda, pueden pertenecen por igual a las dos religiones a las que se pretende acercar el texto.

Empiezo por mencionar la preceptiva religiosa porque "Los castigos..." comienzan con este tipo de amonestaciones. En realidad, este tratado didáctico no puede dividirse abruptamente, en mi opinión, en secciones claramente diferenciadas, ${ }^{21}$ pues se mezclan partes de unas con otras. Pienso que es posible hablar de un proemio y tres temas: la introducción, las normas religiosas y morales, las virtudes que debe poseer un caballero y las virtudes de un buen rey. La estructura de los "Castigos del rey de Mentón" es una progresiva profundización en la preceptiva política. Si bien se parte de la religión

oriental de la más árabe de las partes del Zifar, escribe: "All we can say with confidence is that the Zifar author was undoubtedly familiar with oriental wisdom literature in Spanish translations (as any educated man in Toledo at period must have been, and as his use of the Castilian version of the Flores proves); but whether he knew the Semitic originals of these translations is a question that cannot really be answered" (53-54).

${ }^{20}$ Además de que, sin soslayar las diferencias puntuales que las separan, las tres religiones de España son de inspiración común.

${ }^{21}$ Walker (126-133) hace una división similar a la que yo manejo, pero incluye en lo que llama "series de apertura” y yo "introducción” las normas religiosas y morales que pienso que se separan, basándome precisamente en las divisiones retóricas de los tratados, de la primera parte, porque representan el desarrollo de una idea expuesta por entero en el proemio que es la introducción. 
y se continúa con la moral, no es posible dejar de lado el propósito confeso del libro por servir de guía a futuros gobernantes: Garfín y Roboán y hacerlo por la única vía que se consideró prestigiosa en el momento específico de la escritura de la novela, el camino de la caballería.

La introducción es un pequeño proemio en que se aconseja: 1) amar, servir y temer a Dios, 2) guardar sus mandamientos, 3) honrar a padre y madre, y 4) tomar buen consejo. Esta sección se amplifica mediante tres exempla y aporta una lista de virtudes y otra de pecados. Las virtudes son: caridad, mesura, constancia, vergüenza, fe, verdad, justicia, sapiencia, contrición y paciencia; por su parte los pecados que aparecen son: vanagloria, lujuria, ira, avaricia, glotonería y voluntariedad (233-239).

A partir de este punto, viene la primera parte de la verdadera exposición de los castigos donde se pone de manifiesto la ideología que debe sustentar toda acción. Efectivamente, como hace notar Walker en su estudio, en esta primera sección se presentan en resumen todos los temas que después se desarrollarán, pero, desde mi punto de vista, aquí aparecen muy mediatizados por el enfoque moral y religioso, mientras que más tarde se tratarán directamente. Se ofrecen consejos como la necesidad de aprender buenas costumbres y usarlas $y$, sin que pudiera ser de otra manera, se hace explícita la crítica a la postura de la necesidad de poseer una alta sangre para ser noble: "E creed que con las buenas costunbres en que yazen estas virtudes puede ser dicho noble aquel que de ellas fuere señor, ca dize un sabio: 'nin por el padre nin por la madre non es dicho noble el ome, mas por buena vida e buenas costunbres que aya" "(259). A partir de este punto se vuelve a hablar sobre las virtudes, pero ya no en general, sino de las que debe tener el noble: "pero devedes saber que el noble deve aver en sí estas siete virtudes que de suso diximos..." (259).

A pesar de que resulta clara la intención de abonar posibilidades de prestigio para cualquier persona "de buenas costumbres", el Zifar no deja de pasar de un lado a otro de esta consideración. Apenas un par de líneas después dice: "el noble, quanto más alto, tanto deve ser más omildoso; e quanto es más noble e más poderoso, tanto 
deve ser más omildoso; e quanto más noble e más poderoso, tanto deve ser más mesurado" (258). De donde se puede desprender que la nobleza tiende a tener escalas y a procurar poder; por ende, difícilmente está desprovista de todo matiz social y abocada únicamente al campo moral.

Tras el pequeño desliz, el rey de Mentón continúa aleccionando a sus vástagos sobre cuestiones morales. Cada una de las siete virtudes (humildad, sapiencia, paciencia, abstinencia, franqueza, caridad y amor verdadero) es revisada, pero el texto se permite largas disquisiciones sobre el comportamiento que se debe seguir para tratar con los reyes y ofrece consejos en verdad prácticos como: "E el amor verdadero en sí mesmo comiença, e desí entendervos hedes a los otros faziéndoles bien de lo vuestro e buscándoles pro con vuestro señor en lo que podieres; pero maguer que muy privados seades, guardatvos de lo enojar" (250). O bien: "guardatvos de caer al rey en yerro, ca ellos han por costunbre de contar el muy pequeño yerro por grande, pero que lo ome aya fecho tan gran serviçio luengo tiempo, todo lo olvida a la hora de la saña" (249). Este tipo de consejo, junto con el de cuidarse de intimar demasiado con un gobernante, son los rasgos que prefiguran la manera de obrar en cortes ya no feudales.

Esta parte termina con admoniciones sobre cómo educar a los hijos y la conveniencia de una educación rígida. Es posible que el tan traído y llevado materialismo de los musulmanes se haga presente en los capítulos dedicados a la educación de los hijos y la conveniencia de la riqueza para la mejor defensa de sus posesiones. Actitud que se sitúa a bastante distancia de los propósitos del sermón cristiano, incluso del sermón universitario cristiano. Sin embargo, como ya apunté arriba, en estos terrenos no es posible afirmar tajantemente cosa alguna.

Otro de los temas de "Los castigos..." es el aleccionamiento sobre las cualidades que debe tener todo buen caballero. Es de notar que la primera mención que se hace hacia este estado se refiere ante todo a la función de grupo y carácter de camaradería que tuvo y a su relación con las mujeres: “... e devedes ser conpañeros a todos, grandes e pequeños; e devedes onrar a las dueñas e donzellas 
sobre todas; e quando ovierdes a fablar con ellas, devédevos guardar de dezir palabras torpes nin nesçias, ça reprehenderían luego, porque ellas son muy aperçibidas en parar mientes a lo que dizen e en escatimar las palabras" (256-257).

No es de extrañar; desde el siglo XII para los hombres dejó de ser suficiente el ser un esforzado guerrero. ${ }^{22}$ A partir de ese momento fue necesario, para ser considerado buen partido, el ser además un caballero cortés. La cortesía fue el gran elemento civilizador que hizo del Occidente medieval un lugar habitable. Y ser cortés implicaba ser un entretenido compañero, un conversador hábil y: "bien costunbrados en alaçar e en bofordar e en caçar e en jugar tablas e axedres, e en correr e luchar [...], aprender esgrima" (257). Además de que las maneras de mesa empezaban a ser importantes: "devedes ser mesurados en comer e en bever" (257). Ser cortés implicaba estas cualidades más la discreción, el no mentir y el guardarse de hablar mal, también mencionadas en "Los castigos del rey de Mentón". Sin estas virtudes no había cortesía, y sin ella no podría haber caballero que lo fuera. Pues, como el mismo Zifar anota: "cortesía es suma de las bondades".

En esta preceptiva a caballo entre las intenciones de hacer caballeros o cortesanos, los consejos se amontonan: el buen caballero debe tener paciencia con los más poderosos, debe aprender a sufrir con razón las cosas dañosas que se antojaren, a domeñarse hasta el punto de hacer prevalecer la razón sobre los apetitos, buscar el bien a los otros, ser agradecidos, limpios y castos.

Por lo que toca a los castigos que se abocan a enumerar las virtudes reales y los consejos directos a los futuros gobernantes, se puede empezar por señalar el marcado interés por hacer derivar la legitimidad regia de la voluntad divina. Esta necesidad hace que sea importante hablar sobre la moral del rey y la bondad de sus dones naturales. Básicamente se repiten los mismos preceptos que se han aconsejado a los que quisieran ser nobles y las cualidades que se

${ }^{22}$ Véase mi artículo: "El más hermoso caballero del mundo: acercamiento al héroe artúrico". 
esperan del caballero y no añaden sino minúsculos detalles. Es, sin embargo, en los consejos sobre cómo reinar adecuadamente donde se pueden ver los rasgos más interesantes de este tratado.

Por ejemplo, al hablar de la liberalidad del monarca es muy claro en las razones para asumirla: $:^{23}$

Devedes ser francos de lo que ovierdes en aquellos lugares do entendierdes que cunple, ca franqueza es nobleza de coraçón, e el que es franco es siervo. E comoquier que devedes ser francos en partir lo que ovierdes, devedes ser de buena provisión en guardar lo más que podierdes en non venir a grant mengua; ca, mal pecado, pocos amigos fallaredes al tienpo de agora que voz acorriesen con lo suyo, a grant pro e a grant daño de vos. E quando grant tesoro ovierdes quedar, e asi abredes quedar e así abredes vos omes. Ca sabet que la riqueza es apostura e la pobredat despreçiamiento. (291)

Igualmente, sería de reconsiderar que casi quinientos años antes de la revolución francesa "Los castigos..." proponen: "Ca el rey e su regno son dos personas, e así como una cosa ayuda, dos en uno. $\mathrm{E}$ bien así como el cuerpo e el alma non son una cosa después que son departidos, así el rey y su pueblo non pueden ningunt bien acabar seyendo desabenidos" (277). Una declaración sorprendente en un texto que ha sido acusado de nostálgico, ya que se ubica del lado del rey al pueblo en contra de los abusos y desmanes de los señores feudales, y que, por otra parte, pone en primer plano esta alianza de rey y pueblo contra la nobleza cuyo rompimiento provocó las crisis de las monarquías, pero, antes de apresurarnos a hablar de la democracia del texto y calificarlo de moderno, recordemos el momento en que fue escrito y que esta fue una de las causas capitales para el

${ }^{23}$ La liberalidad del monarca, cimentada muchas veces en la imagen del Rey Arturo, fue una de las principales cartas que usó la monarquía inglesa para minar la imagen de los reyes franceses, siempre tachados de codiciosos y por ello de malos soberanos. 
colapso del sistema feudal que se empezó a derrumbar ante el empuje de las clases burguesas y villanas que buscaron apoyo a sus privilegios en un rey que impulsó sus aspiraciones porque así contribuía a acorralar a sus demasiado poderosos vasallos.

En conclusión, el principal sustento de la preceptiva del Zifar es religioso y un buen exponente de las funciones de la religión cuando era ideología y no sólo práctica. Aunque la ideología sustentante de las normas de "Los castigos del rey de Mentón" sea la religión y todo hecho humano busca su justificación y su lugar en un orden divino, no es posible dejar de notar que, heredero de varios siglos de caballería occidental y otros tantos de oriental, una de las líneas más importantes de la educación de los futuros príncipes y cortesanos es la cortesía y que ésta tiene un papel destacado en la formación del futuro monarca y en su capacidad para desempeñarse con competencia.

En relación con la preceptiva moral, en ese terreno pareciera que sí resulta posible afirmar que algunos de los consejos que Zifar da a sus hijos tienen que ver con un tipo de moralidad más cercana a la oriental que a la occidental. Buen ejemplo de esto puede ser la preocupación por la riqueza pecuniaria, que se aleja del ideal feudal cristiano de la riqueza por posesión de la tierra. ${ }^{24}$

Finalmente, de la preceptiva política podría resultar adecuado decir que el Zifar, aun inscrito dentro de tradiciones diversas, es un buen ejemplo de una amalgama de tendencias que llegaron a conducir hasta obras como El príncipe. Los consejos de índole práctica que Zifar da sus hijos son compartidos por mucha de la preceptiva política que se considera eminentemente renacentista. Y, para Beneyto Pérez, el Zifar presenta "la posición más original y firme"

\footnotetext{
${ }^{24}$ Sin embargo, a este respecto, es importante señalar que si bien puede ser una observación válida para diferentes Estados de la Europa feudal, el caso de la península Ibérica es muy particular. La reconquista propició que los ciclos y las edades feudales no coincidieran con los del resto de la Europa cristiana y tempranamente pueden encontrarse documentos -el Poema de Mio Cid, por ejemplo- que hacen constar la preocupación por el dinero sobrepasando al interés por las posesiones territoriales más difíciles de defender.
} 
de la novelística de temas caballerescos y en "Los castigos...": "se hilvana una teoría de las virtudes (justicia, nobleza, mesura, humildad, obediencia) con un fervor docente, que mezcla el saber con la cortesía" (345-346).

En el periodo en que el Zifar se escribe, el infante don Juan Manuel ha iniciado ya sus preceptivas para príncipes y consejeros. La intención del Zifar y el público al que estuviera dirigido pueden ser similares. Sin embargo mientras don Juan Manuel se dirige a una élite de consejeros y verdaderos educadores de príncipes, es probable que el Zifar estuviese pensado para un público menos elitista, cercano posiblemente a círculos eclesiásticos, en otras palabras, el bajo el clero. Sin embargo la inclusión de la preceptiva dentro del libro de caballerías posiblemente contribuyó a que fuera conocido por un público no siempre interesado en leer lecciones políticas.

Creo que la presencia del tratado que es "Los castigos..." ayuda a ver con mayor claridad algunos objetivos de un autor que pertenece a una época en que aún hay interés por lo que después llamaremos "literatura pura", que necesita expresar un mensaje y que emplea para hacer claro ese mensaje cuanto recurso tiene a la mano. La inclusión de "Los castigos..." creo que desmiente posturas que pretenden ver en el Zifar un exponente anacrónico de tipos de vida y movilidad social ya imposibles. ${ }^{25} \mathrm{Si}$ bien es cierto que el siglo XIV ya no es la época dorada de la caballería y los reinos ya no se ganan fácilmente con hazañas guerreras, sigue siendo un periodo que considera vigentes esas actitudes y hay aún quien práctica la caballería como forma de vida, no como muestra de status. Por otra parte, la preceptiva que ofrecen "Los castigos..." lejos de poder ser considerada inadecuada o anacrónica es, en mi opinión, absolutamente vi-

${ }^{25}$ Cristina González, por ejemplo, habla de que la ideología del Zifar pertenece a una "época anterior [... a] cuando ese tipo de ascenso se estaba haciendo imposible". Para ella, y los historiadores que cita, en el siglo XIV ya la caballería son formas vacías mientras que la novela refleja un estado previo en el cual "el valor era un medio para conseguir un fin y no un fin en sí mismo" (89). 
gente y la historia podría ser testigo de que lo siguió siendo por varios siglos más.

Según como se lea el libro entero, pueden ser interpretados "Los castigos..."; para Burke, aquellos "represents the ideas of the author of the Zifar concerning kingship and government and the place of the ruler within the divine order" (104). No se puede olvidar que él hace una interpretación simbólica sobre la creación de un reino de Dios. Otros lo asimilan a fines cercanos a los arquetipos de sociedad: "Das Modell der politischen Ethik, das El Libro del Caballero Zifar entwickelt, ist daher enger, als bisher angenommen, mit den Vorstellugen verknüpft, die damals in den Fürstens-piegeln und juristischen Werken das Idealbild eines spanischen Herrschers bestimmten" (Blüher 257). Es, afiliándome a la crítica que defiende la unidad de la obra entera, una codificación abstracta de las lecciones prácticas que se pueden leer en el resto del libro. ${ }^{26} \mathrm{La}$ autonomía con que pueden ser leídos "Los consejos..." resulta engañosa, ya que no es posible hacer lo mismo con el Zifar que es, finalmente y aún en una de las secciones que se pueden identificar como provenientes de una tradición específica, una amalgama de posturas, géneros e ideologías orientales y occidentales; entonces, ¿por qué no mejor llamarlas sólo humanas y saludar al Zifar como una ecléctica suma de esas virtudes?

\section{Obras citadas}

Abd-El-Jalil, J.M. Brève histoire de la littérature arabe. Paris: G.P. Maisonneuve Éditeur, 1943.

Blüher, Karl A. "Zur Tradition der politischen Ethik im Libro del Caballero Zifar." Zeitschrift für Romanische Philologie 87 (1971): 249-57.

${ }^{26}$ A pesar de que los estudios más viejos consideraron esta sección como un tratado independiente por su cualidad diferente, estudiosos como Walker no ven en su formulización abstracta ni en su discurso específico un obstáculo para considerarla parte integral y necesaria de la novela. 
Burke, James F. History and Vision. The Figural Structure of the "Libro del Cavallero Zifar." London: Tamesis, 1972.

Diz, Marta Ana. "La construcción del Cifar." Nueva Revista de Filología Hispana 28.1 (1979): 105-17.

González, Cristina. "El cavallero Zifar" y el reino lejano. Madrid: Gredos, 1984.

Libro del Cavallero Zifar. Ed. Joaquín González Muela. Madrid: Castalia, 1982.

El libro del Cauallero Zifar. Ed. Ch. Ph. Wagner. Ann Arbor: University of Michigan, 1927.

Lida de Malkiel, María Rosa. "Arthurian Literature in Spain and Portugal." En Arthurian Literature in the Middle Ages. Ed. R.S. Loomis. Oxford: Clarendon Press, 1959. 406-18.

. La tradición clásica en España. Esplugues de Llobregat: Ariel, 1975.

Menéndez y Pelayo, Marcelino. Origenes de la novela. Ed. E. Sánchez Reyes. Madrid: Consejo Superior de Investigaciones Científicas, 1962.

Morales, Ana María. "El más hermoso caballero del mundo, una aproximación al héroe artúrico." En: Palabra e imagen en la Edad Media. Eds. Aurelio González et al.. México: Universidad Nacional Autónoma de México, 1995. 407-18.

Pérez, Beneyto. Los orígenes de la ciencia política en España. Madrid: Instituto de Estudios Políticos, 1949.

Rey, Agapito. Introducción a El libro de los cien capitulos. Bloomington, Ind.: IUHS, 1960.

Ruiz de Conde, Justina. El amor y el matrimonio secreto en las novelas de caballerías. Madrid: Aguilar, 1948.

Scholberg, Kenneth. "The structure of the Caballero Cifar." MNL 79 (1964): 113-24.

Viguera, María Jesús. Introducción a Ibn Hudayl. Gala de caballeros, blasón de paladines. Ed. M.J. Viguera. Madrid: Editora Nacional, 1977. 9-35.

Wagner, Charles Philip. "The sources of El Cavallero Cifar." Revue Hispanique 10 (1903): 5-104. 
Walker, Roger M. Tradition and Technique in "El Libro del Cavallero Zifar.” London: Tamesis, 1974.

Walsh, John K. "Versiones peninsulares del "Kitāb Ãd̄ab Al-Falāsifa” de Hunayn Ibn Ishāq." Al-Andalus 41 (1976): 355-84. 